\title{
INFORMATION CONTENT ANALYSIS FROM VERY HIGH RESOLUTION OPTICAL SPACE IMAGERY FOR UPDATING SPATIAL DATABASE
}

\author{
M. Alkan ${ }^{\mathrm{a}, *}$ \\ ${ }^{a}$ Department of Geomatics, Faculty of Civil Engineering, Yıldız Technical University, (alkan@ yildiz.edu.tr)
}

Commission IV, WG IV/3

KEY WORDS: Information Content, Topographing Mapping, GIS, Remote Sensing, VHR Images

\begin{abstract}
:
High resolution satellite images started with IKONOS imagery. After the launch of the very high resolution IKONOS in the 1990s, a new generation of commercial Earth-imaging satellites have pioneered a new era of space imaging for observations of Earth. The IKONOS satellite image has an important place sampling range with 1m GSD. In the subsequent Quickbird satellite image, the GSD is down to $62 \mathrm{~cm}$ and the sensitivity is even higher. Advancements in the geometric resolution of space images have improved the conditions for generations of large-scale topographic maps. With using WorldView-1, WorldView-2, and GeoEye-1, images can now be captured from space with a $0.5 \mathrm{~m}$ ground sampling distance (GSD). The Worldview-4 display with the highest technology and resolution is being used in various application areas. WorldView-4 (formerly GeoEye-2), launched in November 2017, provides a second sensor which is capable of delivering imagery at $30 \mathrm{~cm}$ resolution, the highest level of detail commercially available from satellite. WorldView-4 greatly expands the $30 \mathrm{~cm}$ collection capabilities and archive growth in today's imagery environment. Geometric accuracy and information content are the most significant components of mapping from space images. By using economical, rapid and periodic acquisition, and corresponding ground resolution, these satellites have established an alternative to aerial photos and have been widely used for various applications such as object extraction, change detection, topographic map production, and development of Geographic Information Systems (GIS). The utility of VHR images is dependent on their geometric accuracy and information content. Related with the study, the generally required production scale of 0.05 to $0.1 \mathrm{~mm}$ GSD in the map scale has been confirmed. This corresponds to a topographic map scale of 1:10,000 respectively 1:5000 for $1 \mathrm{~m}$ and $0.5 \mathrm{~m}$ GSD images. In this study, images from IKONOS, QuickBird, WorldView-1, Worldview-2 and WorldView-4 have been used for topographic mapping. For this reason, İstanbul and Zonguldak test fields are an important area for applications of the high resolution imageries. The details which can be identified in the space images dominantly depends upon the ground resolution, available as ground sampling distance (GSD). In this study, high resolution imageries have been tested depending on the GSD and corresponding to the map scales for updating GIS database.
\end{abstract}

\section{INTRODUCTION}

In the most recent years, after the launch of very high resolution optical satellites, a new era of Earth observation began all over the world (Alkan et.al, 2013; Li, 1998). Very high resolution (VHR) optical satellite imagery has been used for several applications such as object extraction, change detection, topographic map production, and development of Geographic Information Systems (GIS). One of the important applications is the generation and updating of GIS databases by topographic mapping which depends on the presentation scale (Jacobsen, 2002; Jacobsen et al.,2008; Ahmadi et al.,2010; Mondino \& Chiabrando, 2010). The use of Geographic Information Systems (GISs) together with Remote Sensing became important. The generating of topographic maps is a major application. Aerial imagery or very high resolution optical space imageries can be used for generation or be updating GIS databases depending upon the required accuracy (Alkan et al., 2010, Jacobsen, et al., 2008; Topan, et al., 2009; Topan et al., 2005; Aquilar et al., 2008). Up to date, the number and capacity of very high resolution optical satellites grow permanently, so the access to very high resolution space images is not anymore a problem (Alkan et al., 2013; Jacobsen et al., 2008; Topan et al., 2005). Because of the very high resolution of optical space imageries they can be used instead of aerial imagery depending on the required information contents and accuracy (Jacobsen, et al., 2008; Topan et al., 2005; Alkan et al., 2010; Topan et al., 2009; Aquilar et al., 2008).

The information contents and the geometric accuracy are important for the generation of qualified topographic maps. For the city of Zonguldak, Turkey, besides other space imagery, images from IKONOS, QuickBird and WorldView-1 and Istanbul, Turkey, imageries from Worldview-2 and Worldview4 are available and have been used for topographic mapping. The information contents and the geometric accuracy are important issues for large scale topographic map generation. In the last years, very high-resolution satellite imageries as Worldview-1 and -2 and -4 often have been used as well as IKONOS and Quickbird. Traditionally the mapping was based on aerial images being difficult because of legal classification limitations in Turkey. With the today available very high resolution space images with up to $0.5 \mathrm{~m}$ ground sampling distance (GSD) it is possible to use space images instead of aerial images. They have the advantage of simple availability and are not restricted by classification (Buyuksalih et al., 2008, Jacobsen et al., 2008). With the today available very high resolution space images with up to $0.31 \mathrm{~m}$ ground sampling distance (GSD) it is possible to use space images instead of

*Corresponding Author 
aerial images. They have the advantage of simple availability and are not restricted by classification (Figure1, 2).

In this study, Istanbul city and Zonguldak city, located in the North-West part of Turkey is selected as a test field. Istanbul is located in between the Western Black Sea and Marmara Sea region of Turkey. Zonguldak is located in Western Black Sea region of Turkey. Istanbul is the biggest city in Turkey. Istanbul also has a Bosphorus, which is the road that connects the Black Sea and the Sea of Marmara. Istanbul has a wide variety of topographical structures, which can be listed as flat, sloping, coastal, lake and lakesides. Zonguldak is the most important coal mining area of Turkey. The area has a rolling up to mountainous topography. Beside built areas at the coast, there are agricultural parts and forests in the inner part of the region. Caused by the steep terrain shadows problems for object identification especially in the city areas.

Related with the study, the generally required production scale of 0.05 to $0.1 \mathrm{~mm}$ GSD in the map scale has been confirmed. This corresponds to a topographic map scale of $1: 10,000$ respectively 1:5000 for $1 \mathrm{~m}$ and $0.5 \mathrm{~m}$ GSD images. In this study, images from IKONOS, QuickBird, WorldView-1, Worldview-2, and WorldView-4 have been used for topographic mapping. For this reason, İstanbul and Zonguldak test fields are an important area for applications of the high resolution imageries. The details which can be identified in the space images dominantly depends upon the ground resolution, available as ground sampling distance (GSD). In this study, high resolution imageries have been tested depending on the GSD and corresponding to the map scales for updating GIS database.

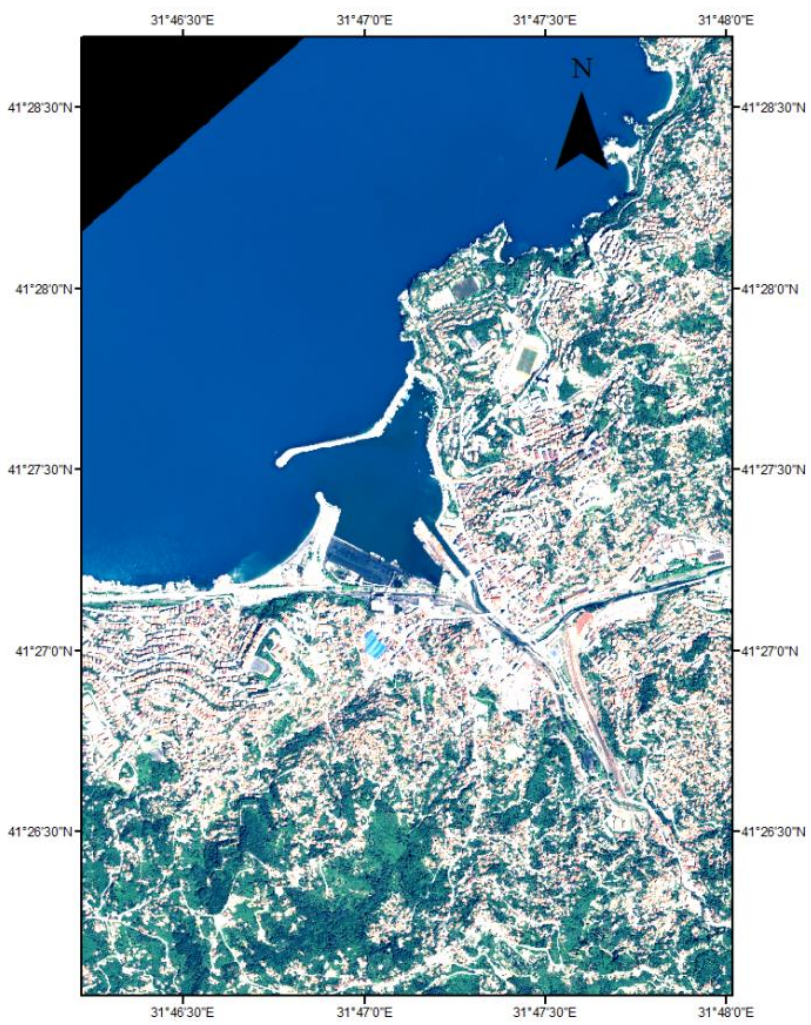

Figure 1. Test site from Zonguldak on Quickbird pansharpened VHR satellite imagery

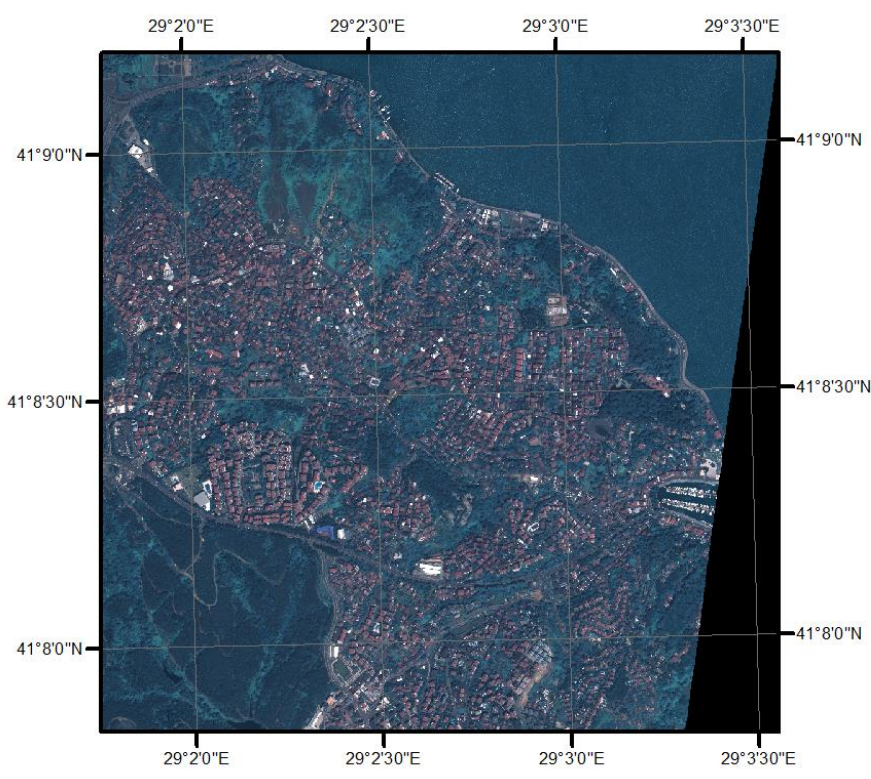

Figure 2. Test site from Istanbul on Worldview-4 VHR satellite imagery

\section{NOMINAL RESOLUTION AND EFFECTIVE GSD}

The important issue is geometric resolution with topographic mapping and object identification. The smaller the GSD the more detailed information can be extracted. For instance, more objects with more detail can be seen in the very high resolution Worldview-4 images with $0.31 \mathrm{~cm}$ GSD than in IKONOS images with $1 \mathrm{~m}$ GSD (figure 1,2). IKONOS images has small large buildings can be recognized while Worldview-4 images show more detail. On the other hand, it could be seen the same details comparing with panchromatic Quickbird, IKONOS, Worldview-1 and Worldview-4 imageries (figure 3 and 4.).

The Ground Sampling Distance is the distance of neighboured pixel centers in object space. Neighboured pixels may be oversampled or under-sampled. The smaller the GSD the more detailed information can be extracted. For instance, more objects details can be seen in the very high resolution Worldview-1 images with $0.5 \mathrm{~m}$ GSD as in Worldview-4 images with $0.31 \mathrm{~m}$. In IKONOS images only large buildings can be recognized while Worldview-1 images show even details at small buildings. Similar details as in WorldView-4 images can be seen in Worldview-1 scenes, while IKONOS images are still affected by the larger GSD.

The nominal ground resolution must not be identical to the effective; especially space images with staggered CCDs (50\% oversampling) may have a lower image quality, leading to reduced effective ground resolution. The effective GSD can be analyzed by edge detection (Jacobsen, 2008). Neighbored pixels may be over-sampled or under-sampled. Table 1 shows the result of an edge analysis; the nominal resolution corresponds for the used images to the effective resolution. 

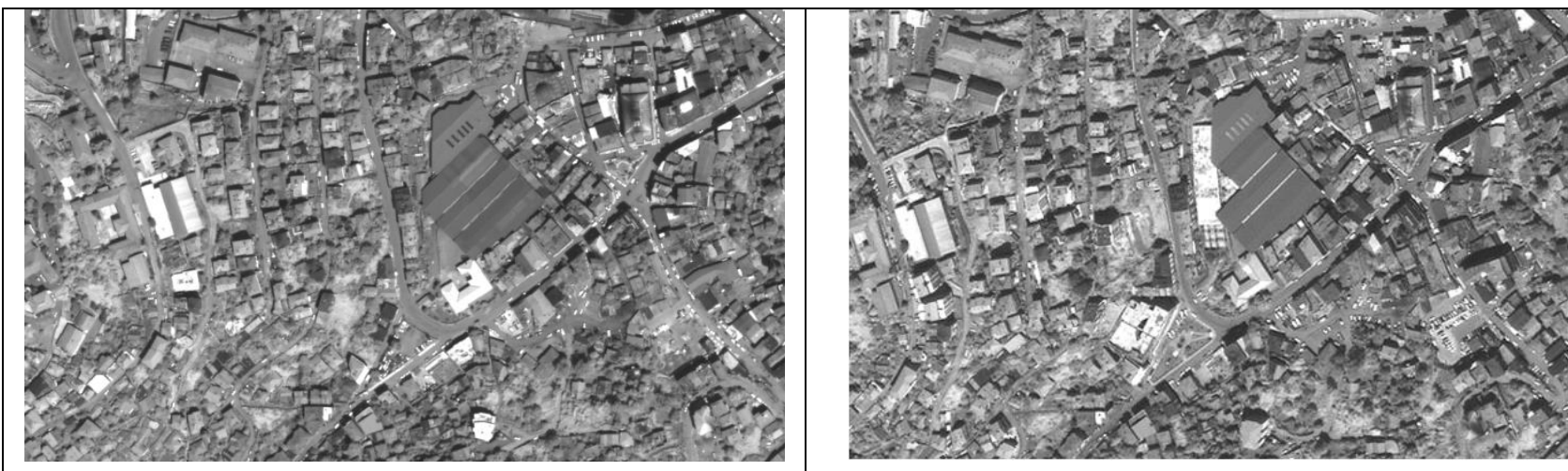

Figure 3. Panchromatic Quickbird image (left), panchromatic IKONOS image - same area (right)
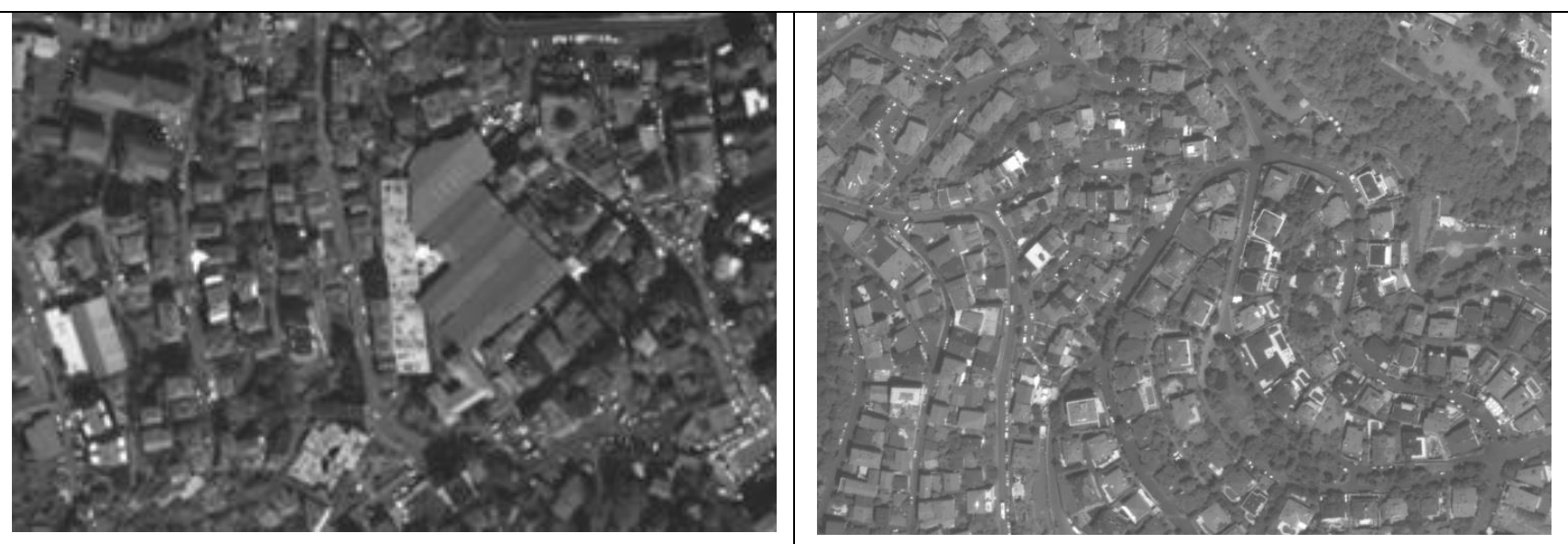

Figure 4. Panchromatic Worldview-1 image (left), Worldview-4 image (right)

\begin{tabular}{|l|c|c|}
\hline & $\begin{array}{c}\text { Nominal pixel } \\
\text { size }(\mathrm{m})\end{array}$ & $\begin{array}{c}\text { Effective pixel size } \\
(\mathrm{m})\end{array}$ \\
\hline IKONOS & 1 & 1 \\
\hline Quickbird & 0.6 & 0.6 \\
\hline Worldview-1 & 0.5 & 0.5 \\
\hline Pleiades & 0.5 & 0.5 \\
\hline Worldview-2 & 0.5 & 0.5 \\
\hline Worldview-4 & 0.31 & 0.31 \\
\hline
\end{tabular}

Table 1. Nominal and effective GSD determined by edge analysis

\section{INFORMATION CONTENT ANALYSIS}

A simple comparison of the different space images gives a good impression about the information contents. Figure 5 shows high resolution optical satellite images with approximately the same number of pixels of the Istanbul city area. Also, Figure 6 shows from Zonguldak city area. The dominating figure for the object identification is the GSD, but the color simplifies the interpretation. IKONOS with $1 \mathrm{~m}$ GSD allows the identification of larger buildings, but it is easy to extract the objects. On the other hand, IKONOS, Quickbird, Worldview-1 and Worldview2 imageries have with $1 \mathrm{~m}$ and below a satisfying GSD for the identification of buildings. Worldview- 4 has a $0.31 \mathrm{~cm}$ GSD below $0.5 \mathrm{~m}$. color simplifies the identify for object details.

In figure 5 windows of space images with approximately the same number of pixels from the city area of Istanbul can be compared. The dominating factor for the object identification is the GSD, but the color simplifies the interpretation. A simple comparison of the different space images gives a good impression about the information contents. Worldview-2 with $0.5 \mathrm{~m}$ GSD allows to details of the object. Worldview-4 has more details from digital images with $0.31 \mathrm{~m}$ GSD. On the other hand, in Zonguldak test area IKONOS, Quickbird, and Worldview-1 imageries have with $1 \mathrm{~m}$ and below a satisfying GSD for the identification and mapping of buildings, with Quickbird and Worldview-1, the mapping of building extensions is simpler as with IKONOS.

The pan-sharpened IKONOS image in figure 7 is affected by shadows. Because of this, especially road network extraction is very difficult in the narrow and inclined streets. The better ground resolution of Quickbird and the higher sun elevation simplifies the object extraction. Even with $2.4 \mathrm{~m}$ GSD in Quickbird color imageries, the buildings can be seen without problems (figure 8). The $0.5 \mathrm{~m}$ GSD of Worldview-1 and Wordview-2 simplifies the mapping of buildings (Figure 9, 10). Also, Worldview-4 has a very high GSD and very good object extraction compared with $1 / 5000$ scale topographic mapping (Figure 11.). For this reason, Worldview-4 is allowing with $1 / 2500$ scale topographic map. The VHR IKONOS, QuickBird, Worldview-1, Worldview-2 and Worldview-4 images with $1 \mathrm{~m}$, $0.6 \mathrm{~m}, 0.5 \mathrm{~m}$ and $0.31 \mathrm{~m} \mathrm{GSD}$, enable a competition to aerial images. QuickBird images can be compared with aerial images having a scale of 1:30 000, allowing the detailed mapping of building extensions. A major advantage of the multispectral bands is the improved potential for object recognition and interpretation. Figure 7, 8, and 9 show the on-screen vectorization results with IKONOS, QuickBird, Worldview-1. Figure 10 and 11 shows on the comparing between 1/5000 scale topographic map and Worldview-2, Worldview-4 pan- 
sharpened images. All of the comparing with the allowing mapping up to the topographic map scale of 1: 10000 respectively 1:2500. The Worldview-4 satellite image has the best resolution and the ability to distinguish the best object in both panchromatic and color image.

As a summary for topographic mapping and updating with very high resolution optical space imagery, the required GSD for the identification of object types in panchromatic images are listed

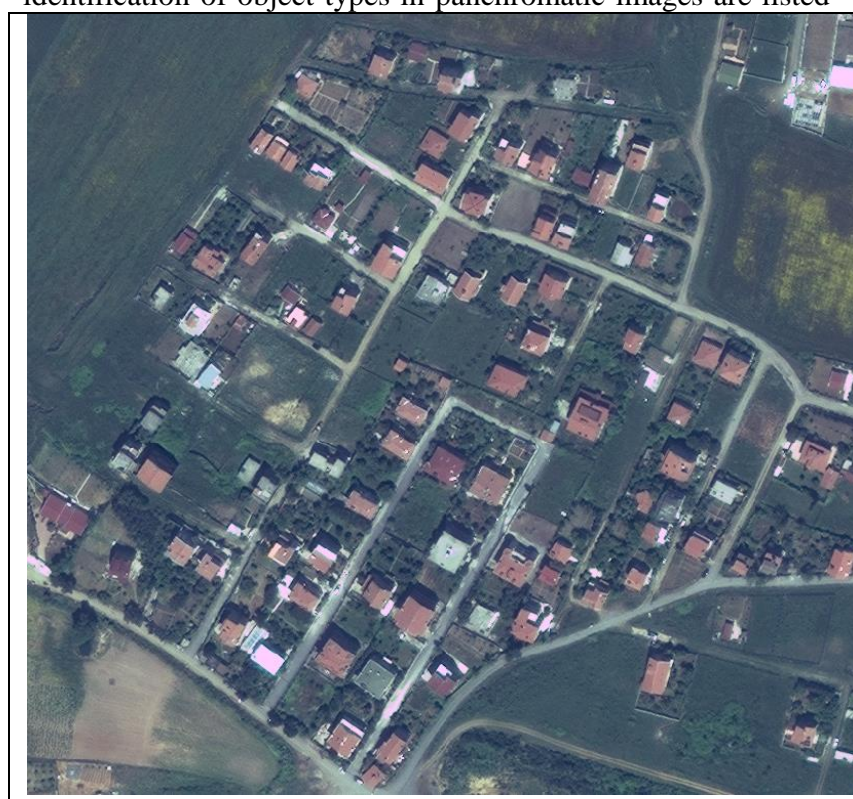

Worldview-2, 0.5m GSD in table 2. The rule of thumb of 0.05 up to $0.1 \mathrm{~mm}$ pixel size in the map scale has been confirmed. Most details required for the map scale 1:10000 have been identified in the build-up areas. The required higher degree of details for mapping in 1/2500 can be extracted from Worldview-4 with $0.31 \mathrm{~cm}$ GSD, 1:5000 can be extracted from WorldView-1 and 2 images with $0.5 \mathrm{~m}$ GSD as well as from the $0.61 \mathrm{~m}$ GSD of Quickbird.

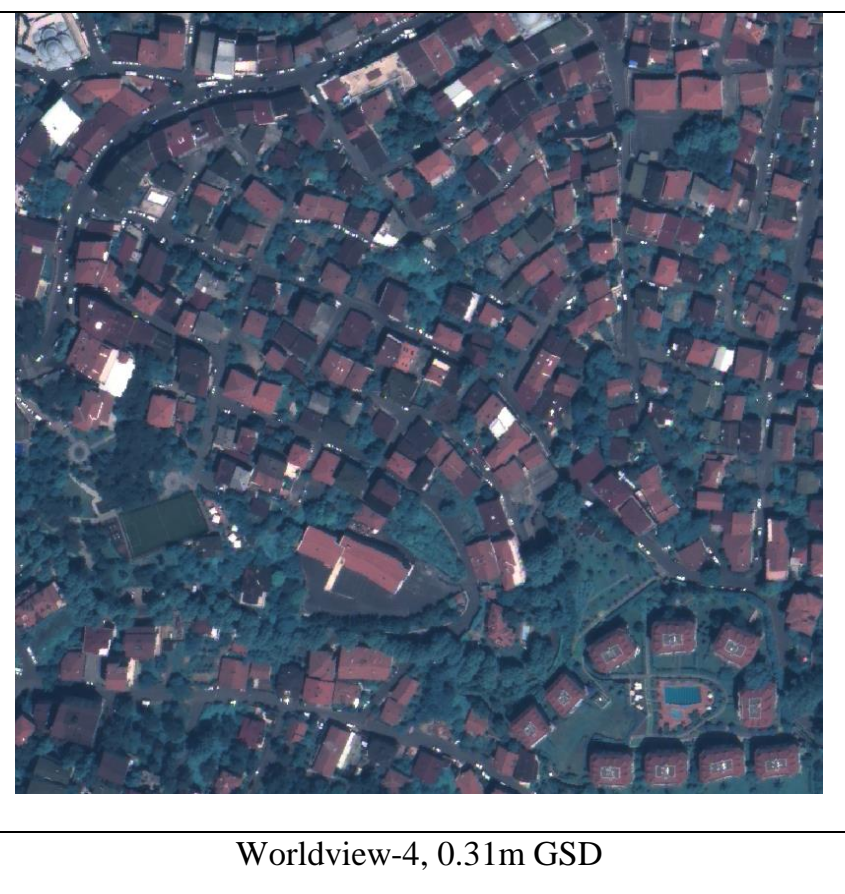

Figure 5. Very high resolution space images of Istanbul test area

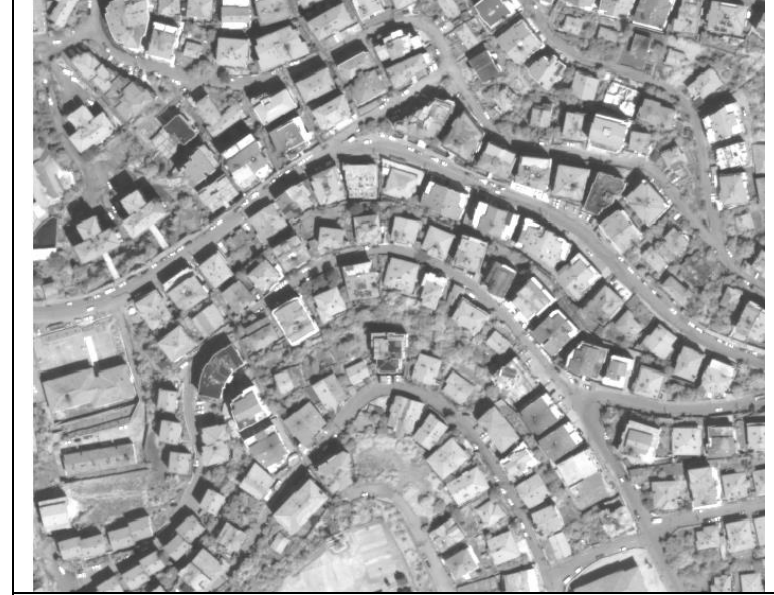

Quickbird, 0.61m GSD

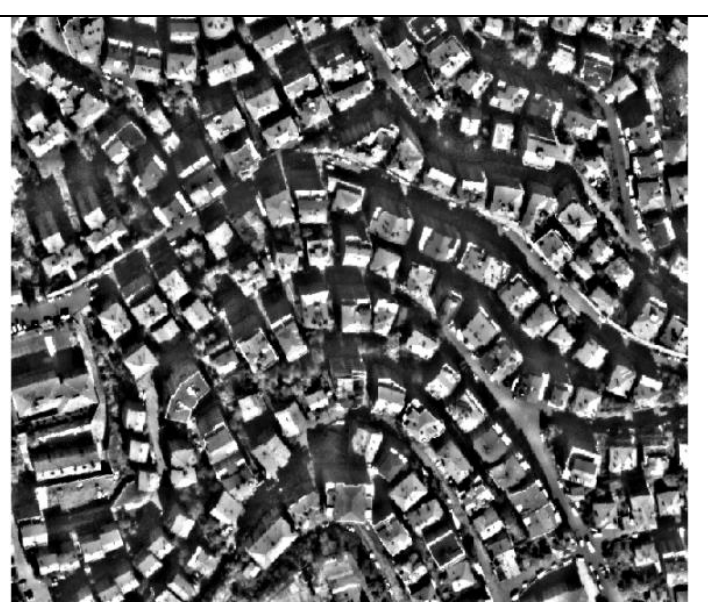

Worldview-1, 0.5m GSD

Figure 6. Very high resolution space images of Zonguldak test area

\begin{tabular}{|l|l|l|}
\hline Objects & Required pixel size & Map Scale \\
\hline Buildings and roads & $0.31 \mathrm{~m}$ or lower GSD & $1: 2500$ \\
\hline Railway & $0.31 \mathrm{~m}$ or lower GSD & $1: 2500$ \\
\hline Buildings and roads & $0.6 \mathrm{~m}$ or lower GSD & $1: 5000$ \\
\hline Railway & $0.6 \mathrm{~m}$ or lower GSD & $1: 5000$ \\
\hline Buildings and roads & $1.0 \mathrm{~m}$ GSD & $1: 10.000$ \\
\hline Railway, minor networks major road & $1.0 \mathrm{~m}$ GSD & $1: 10.000$ \\
\hline $\begin{array}{l}\text { Building blocks, } \\
\text { network }\end{array}$ & $1: 25.000$ \\
\hline
\end{tabular}

Table 2. Required GSD for topographic mapping based on panchromatic images 


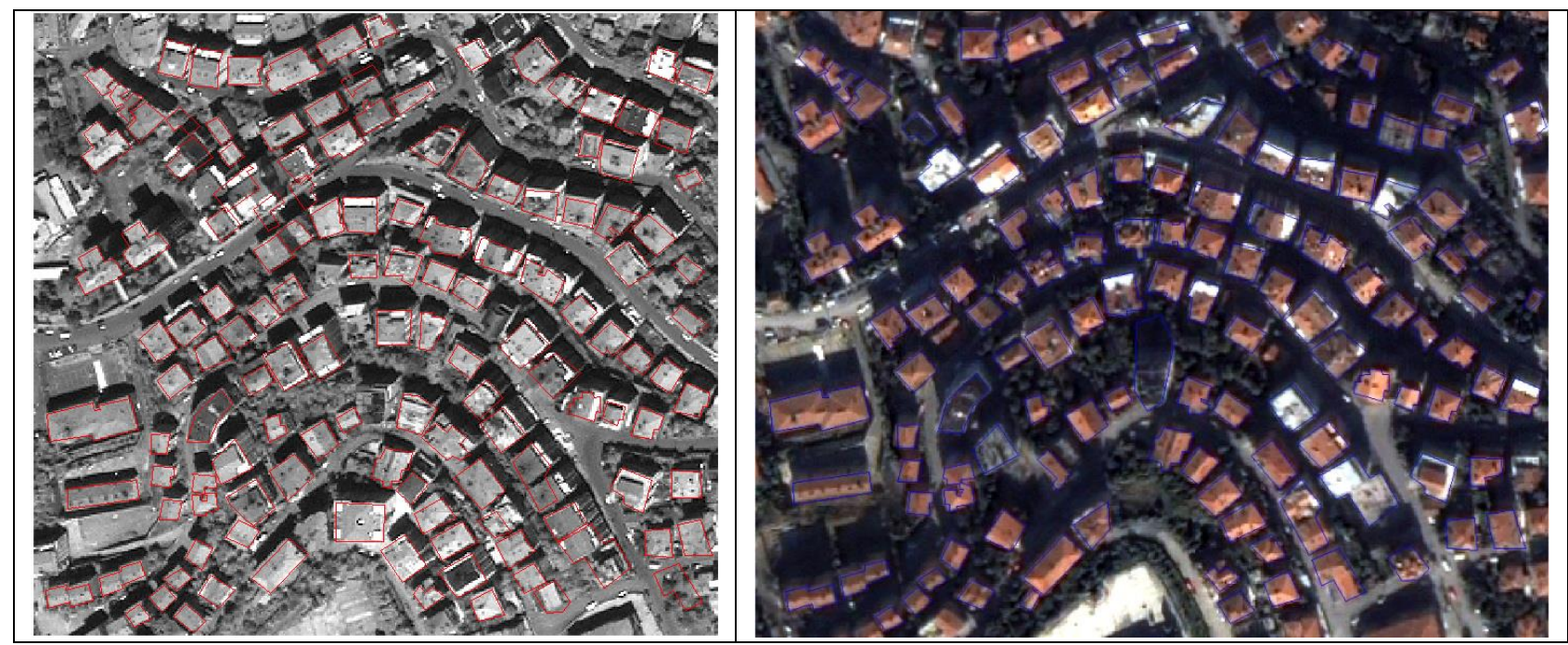

Figure 7. Object extraction from IKONOS pan and pan-sharpened images

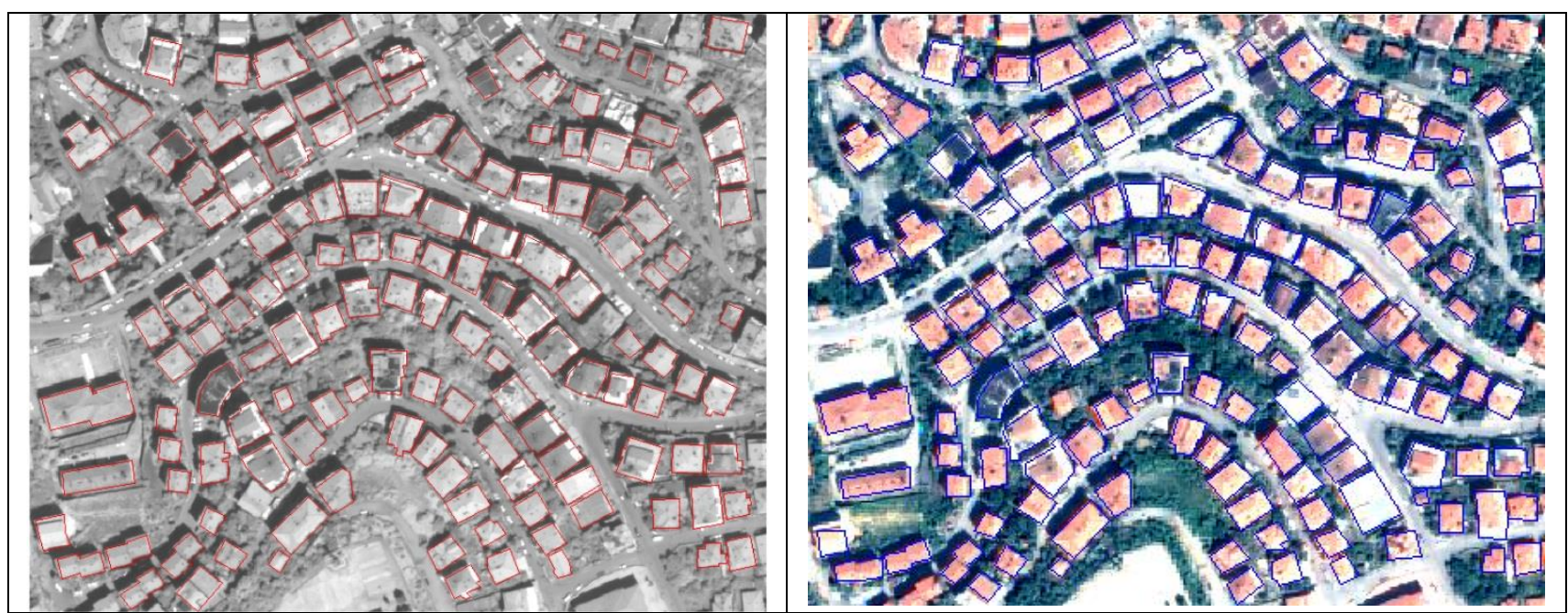

Figure 8. Object extraction from Quickbird pan and pan-sharpened images

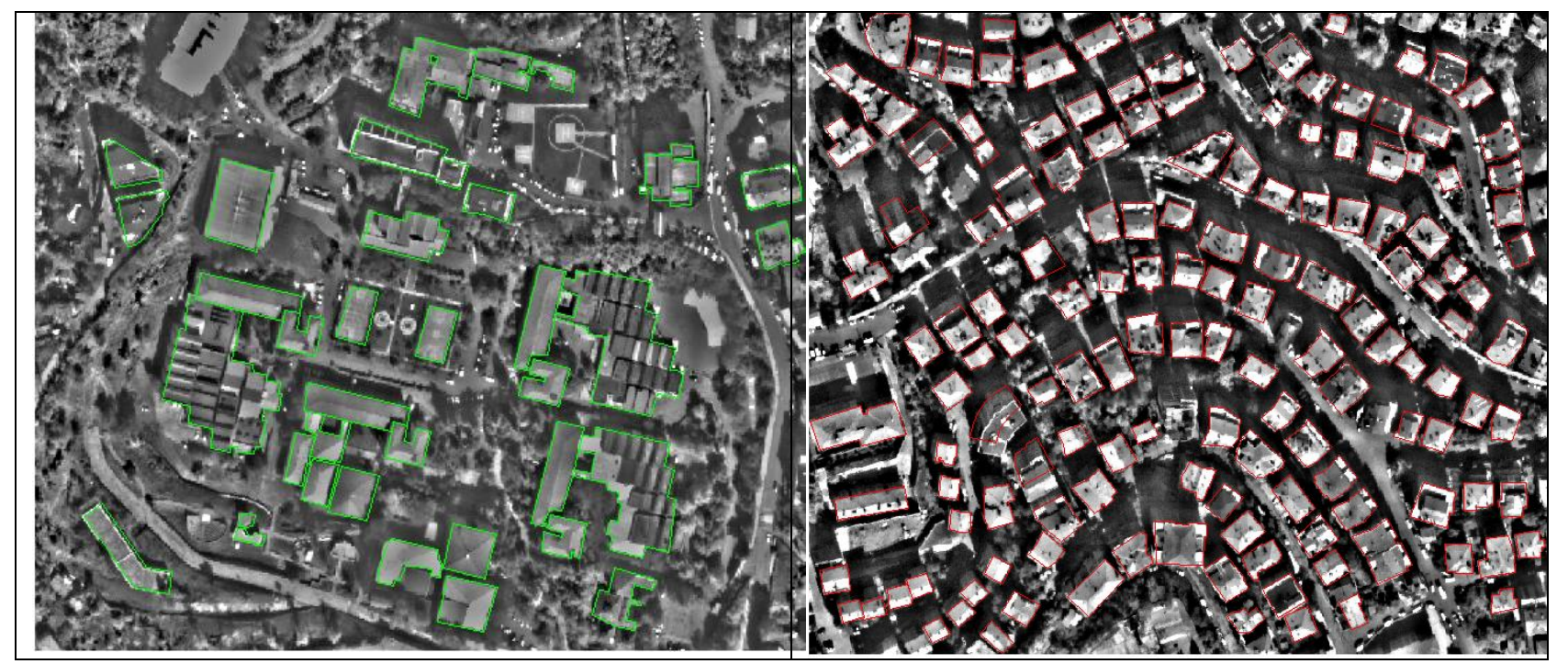

Figure 9. Object extraction from Worldview-1 image in the area of the Zongulak University (left) and a build up area (right) 


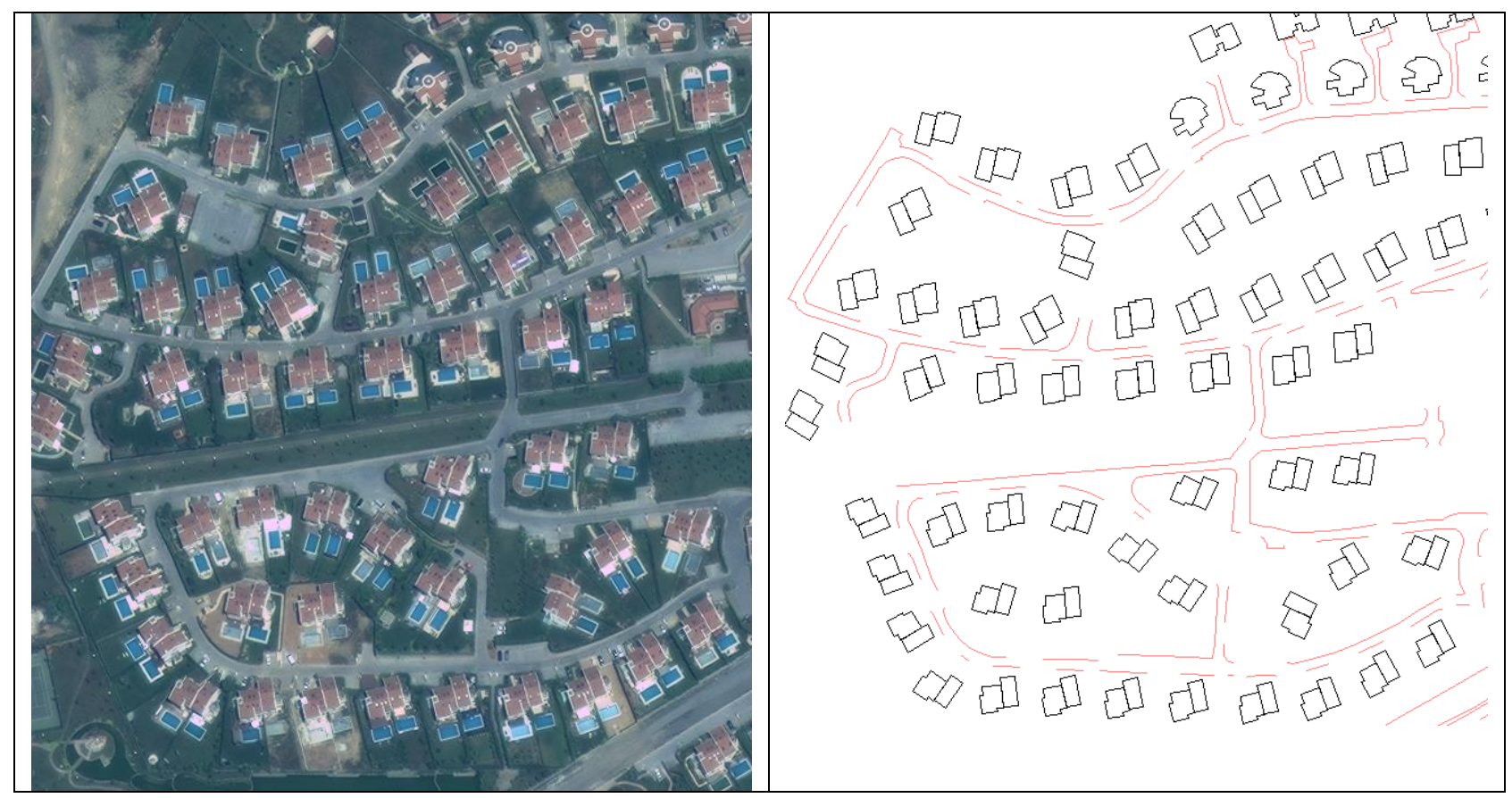

Figure 10. Object comparing with Worldview-2(left) image and 1/5000 scale Topographic map (right) in the area of the Istanbul

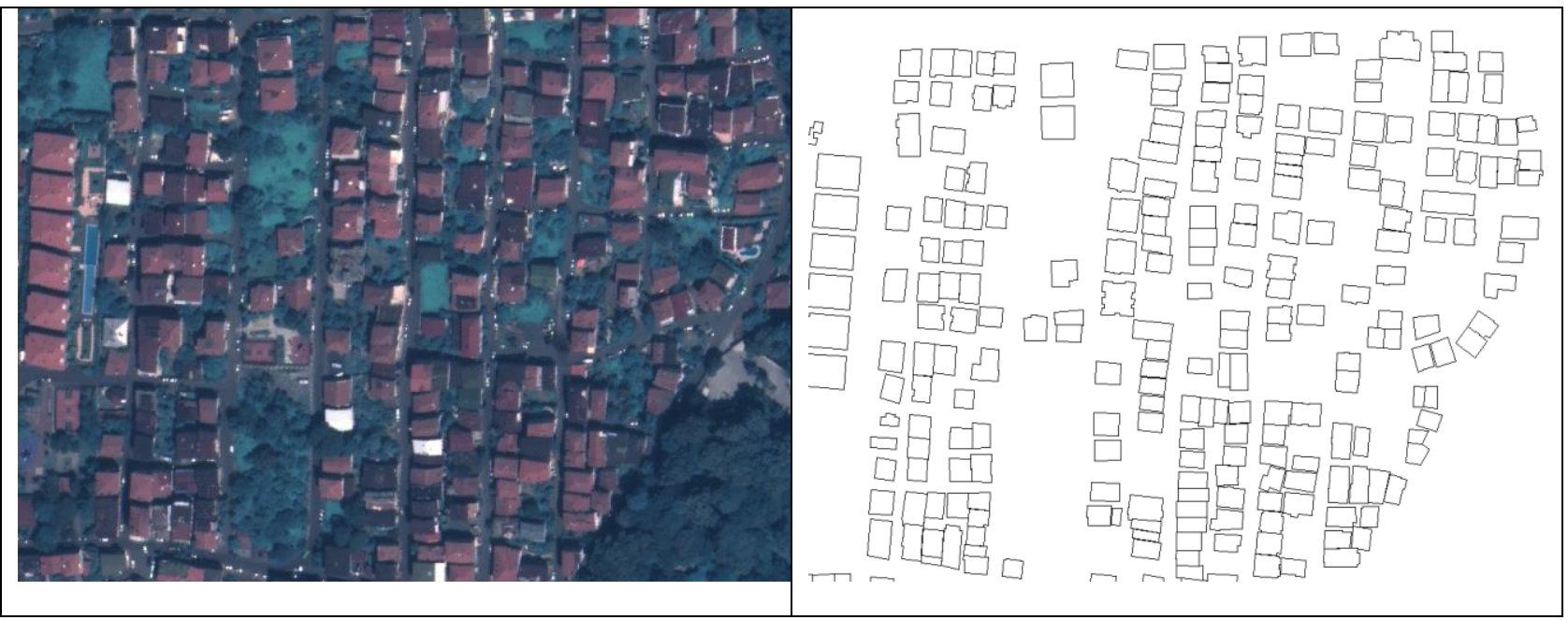

Figure 11. Object comparing with Worldview-4(left) image and 1/5000 scale Topographic map (right) in the area of the Istanbul

\section{CONCLUSION}

In this study, mapping and GIS database update is limited by the information content of the used images. With the very high ground resolution of the current optical space imagery aerial images can be avoided for the map scales 1:5000 and smaller. The rule of thumb for the GSD of 0.05 up to $0.1 \mathrm{~mm}$ in map scale has been confirmed for the used panchromatic images. With color images, the interpretation is quite an easier, but no more details can be extracted. The major limitation for mapping purposes is the image resolution and image quality. The required accuracy of $0.25 \mathrm{~mm}$ in the publishing scale can be reached without problems.

Finally, the extracted buildings clearly demonstrate that IKONOS, Quickbird, WorldView-1, WorldView-2 and WorldView-4 images, with $1 \mathrm{~m}, 0.61 \mathrm{~m}, 0.5 \mathrm{~m}$ respectively 0.31 $\mathrm{m}$ GSD, can be used for mapping and map update for maps with a scale of $1: 10.000$ to $1: 2500$ in the used area. The Worldview4 display with the highest technology and resolution is being used in various application areas. WorldView-4 (formerly GeoEye-2), launched in November 2017, provides a second sensor which is capable of delivering imagery at $30 \mathrm{~cm}$ resolution, the highest level of detail commercially available from the satellite. WorldView-4 greatly expands the $30 \mathrm{~cm}$ collection capabilities and archive growth in today's imagery environment. Geometric accuracy and information content are the most significant components of mapping from space images. However, in any case, there are some limitations as well as the known limitations for mapping from aerial images, which for special topics require field checks. 


\section{ACKNOWLEDGEMENTS}

Acknowledgements of support for the Yildiz Technical University, Office of Scientific Research Project Coordination.
Topan, H., Maktav, D., Jacobsen, K., Buyuksalih, G., 2009. Information Content of Optical Satellite Images for Topographic Mapping, International Journal of Remote Sensing, 30(7), pp. 1819-1827.

\section{REFERENCES}

Aguilar, M.A., Aguilar, F.J., Agüera, F., 2008. Assessing geometric reliability of corrected images from very high resolution satellites, Photogrammetric Engineering \& Remote Sensing, 74(12), pp. 1551-1560.

Ahmadi, S., Valadan Zoej, M.J., Ebadi, H., Moghaddam, H.A., Ali M., 2010. Automatic urban building boundary extraction from high resolution aerial images using an innovative model of active contours, International Journal of Applied Earth Observation and Geoinformation Papers, 12(3), pp. 150-157.

Alkan, M., Sefercik, U.G, Marangoz, A.M., Karakis S., 2010. Updating Object for Topographic Map Information Using High Resolution Satellite Images of Zonguldak Testfield, Proc. 30th EARSeL Symposium, Remote Sensing for Science, Education and Culture.

Alkan, M., Buyuksalih G., Sefercik U.G, and Jacobsen J., 2013. Geometric accuracy and information content of Worldview-1 images, Optical Engineering Papers, 52(2), pp. 026201-1 and 026201-7.

Buyuksalih, G., Jacobsen, K., Baz, I., 2008. Determination of the build-up area development in the Greater Municipality of Istanbul by space images, Proc. EARSel Workshop Remote Sensing - New Challenges of High Resolution, unpaginated CD-ROM.

Jacobsen, K., 2002. Comparison of High Resolution Mapping from Space, Proc. INCA workshop, unpaginated CD-ROM.

Jacobsen, K., Buyuksalih, G., Baz, I., 2008. Mapping From Space for Developing Countries, Proc. EARSeL Joint Workshop: Remote Sensing - New Challenges of High Resolution, unpaginated CD-ROM.

Jacobsen, K., 2008. Tells the number of pixels the truth? Effective Resolution of Large Size Digital Frame Cameras, Proc. ASPRS 2008 Annual Convention, Portland, unpaginated CD-ROM.

Li, R., 1998. Potential of High-Resolution Satellite Imagery for National Mapping Products, Photogrammetric Engineering \& Remote Sensing Papers, 64(12), pp. 1165-1169.

Mondino, E. B., Chiabrando, F., 2010. GeoEye vs. QuickBird: operational potentialities, limits, and integration for fast map production, Proc. SPIE 7831, 78310F. [DOI: http://dx.doi.org/10.1117/12 .865006].

Topan, H., Buyuksalih, G., Jacobsen, K., 2005. Information Contents of High Resolution Satellite Images, Proc. EARSeL Workshop on 3D Remote Sensing, unpaginated CD-ROM. 